\title{
Prognostic significance of HER2/neu, p53, and vascular endothelial growth factor expression in early stage conventional adenocarcinoma and bronchioloalveolar carcinoma of the lung
}

\author{
Reda S Saad ${ }^{1}$, Yulin $\mathrm{Liu}^{1}$, Helen Han ${ }^{1}$, Rodney J Landreneau ${ }^{2}$ and Jan F Silverman ${ }^{1}$ \\ ${ }^{1}$ Department of Pathology, Allegheny General Hospital, Pittsburgh, PA, USA and ${ }^{2}$ Department of Thoracic \\ Surgery, University of Pittsburgh Medical Center, Pittsburgh, PA, USA
}

\begin{abstract}
In this study, we investigated the prognostic value of HER2/neu, p53, and vascular endothelial growth factor in early stage conventional adenocarcinoma and bronchioloalveolar carcinoma of the lung. We studied 100 patients and consisted of 50 cases with conventional adenocarcinoma and 50 cases with bronchioloalveolar carcinoma (32 nonmucinous and 18 mucinous subtypes). Representative sections were immunostained for HER2/neu, p53, and vascular endothelial growth factor. Positivity was scored quantitatively by three observers and correlated with multiple prognostic parameters including survival. In the conventional adenocarcinoma, HER2/neu, p53, and vascular endothelial growth factor were expressed in 19/50 (38\%), 32/50 (64\%), 33/50 (66\%), respectively. In this group, p53 showed a significant correlation with recurrence while vascular endothelial growth factor correlated with angiolymphatic invasion $(P<0.05)$. HER2/neu, p53, and vascular endothelial growth factor expression was associated with significantly shorter survival (log rank, $P<0.05$ ). Patient whose tumors coexpressed both p53 and HER2/neu had the worst outcome. In the bronchioloalveolar carcinoma, HER2/neu, p53, and vascular endothelial growth factor were expressed in 9/50 (18\%), 3/50 (6\%) and 12/50 (24\%), respectively which was significantly less than in conventional adenocarcinoma $(P<0.05)$. HER2/neu positivity showed a significant correlation with shorter survival (log rank, $P<0.05)$ in nonmucinous type. In conclusion, vascular endothelial growth factor was associated with angiolymphatic invasion and poor prognosis in conventional adenocarcinoma. Also, in conventional adenocarcinoma, p53, and HER2/neu expression appeared to be poor prognostic markers, while in bronchioloalveolar carcinoma, only HER2/neu was associated with a poorer prognosis. This immunostaining pattern suggests that conventional adenocarcinoma has different molecular abnormalities than bronchioloalveolar carcinoma.
\end{abstract}

Modern Pathology (2004) 17, 1235-1242, advance online publication, 28 May 2004; doi:10.1038/modpathol.3800171

Keywords: HER2/neu; p53; VEGF; bronchioloalveolar carcinoma; lung adenocarcinoma

Lung cancer is the leading cause of cancer-related deaths in Western countries, even with new diagnostic and treatment modalities. ${ }^{1,2}$ In the United States, approximately 171000 new cases of lung cancer are diagnosed each year, and the overall 5 -year survival remains less than $15 \% .^{3}$ Non-smallcell lung cancer accounts for approximately $80 \%$ of all lung cancers. ${ }^{4}$ In the last two decades, adenocarcinoma has been shown to be significantly

Correspondence: Dr RS Saad, MD, PhD, Department of Pathology and Laboratory Medicine, Louisiana State University Health Science Center, School of Medicine, 1901 Perdido Street, P5-1 New Orleans, LA 70112, USA.

E-mail: redasaad2@hotmail.com

Received 17 December 2003; revised 9 March 2004; accepted 11 March 2004; published online 28 May 2004 increasing in both women and men. ${ }^{5}$ Although tumor stage has a significant role in predicting survival, patients with the same stage may have different outcomes, ${ }^{6}$ urging the need for new reliable predictors of the disease relapse and survival. ${ }^{6,7}$ These markers would be of value in optimizing the medical management of patients at high risk for disease recurrence and/or short survival.

HER2/neu (also known as erb-2) is a member of the erbB gene family and encodes for transmembrane receptor-type tyrosine-protein kinases. ${ }^{8,9}$ Although HER2/neu has been studied most extensively in the breast, ${ }^{10,11}$ there is only a limited amount of information regarding its prognostic value in lung cancer. ${ }^{7}$ p53 is a tumor suppressor gene, located on chromosome $17 \mathrm{p} 13 .{ }^{12}$ The product of this gene is a nuclear protein involved in the 
control of cell cycle activation, apoptosis, and maintenance of genomic stability. ${ }^{12}$ The altered protein from the mutant gene has an extended half-life and can be detected with immunohistochemical techniques. ${ }^{7,13}$ Loss of tumor suppressor function of p53 has been identified in different types of human cancer including cancer of the lung., ${ }^{7,14}$ Vascular endothelial growth factor (VEGF) is an angiogenic factor, produced by the tumor cells to stimulate intratumoral microvessel proliferation (neoangiogenesis). Tumor angiogenesis contributes to the metastatic process by providing large numbers of leaking blood vessels for vascular invasion. ${ }^{7,16}$

Some studies have indicated that mutations in tumor suppressor genes, such as p53, and/or amplifications of oncogenes, such as HER2/neu, are implicated in the pathogenesis of human lung cancer and have been associated with tumor aggressiveness and poor prognosis., ${ }^{77-19}$ Others have either failed to demonstrate this association or show conflicting results. ${ }^{20-22}$

The objective of this study is to investigate the prevalence and prognostic significance of the expression of HER2/neu, p53, and VEGF in a series of patients with stage I adenocarcinomas of conventional and bronchioloalveolar types. Multiple parameters including survival were tested in this study with a long-term follow-up of patients to determine if these immunohistochemical markers can be useful prognostic markers.

\section{Materials and methods}

\section{Patients Selection}

We studied 100 unselected patients with primary stage I lung adenocarcinoma, underwent complete surgical resection in a 5-year period at Allegheny General Hospital from 1996 to 2000. Institutional board review committee approved the study. No chemotherapy or radiotherapy was received. Complete follow-up information was available on all patients.

\section{Pathological Study}

The surgically resected tumors were fixed in $10 \%$ formalin- and paraffin-embedded. Sections, $4 \mu \mathrm{m}$ thick were stained with hematoxylin and eosin for routine histologic examination and reviewed by three investigators (RSS, HH, and YL). Any discrepancies were resolved by joint review of the slides through a multiheaded microscope.

Cases were classified into two groups according to the major morphologic pattern: conventional adenocarcinoma group: 50 patients with invasive adenocarcinoma, encompassing acinar, papillary, and/or solid adenocarcinoma patterns. Bronchioloalveolar carcinoma group: 50 patients with bronchioloalveolar growth pattern tumors, including
32 nonmucinous subtype and 18 mucinous subtype. According to WHO classification (1999), ${ }^{23}$ bronchioloalveolar carcinoma is defined as adenocarcinoma with a pure bronchioloalveolar growth pattern and has no evidence of vascular, pleural, or stromal invasion.

Postoperative pathologic staging was performed according to the staging system of American Joint Committee on Cancer. ${ }^{24}$ In conventional adenocarcinoma patients, the disease stage was IA in 23 and IB in 27 patients and bronchioloalveolar carcinoma patients included stage IA in 34 patients and stage IB in 16 patients. Disease survival was calculated from the date of surgery to the date of progression or the date of last follow-up. Death from lung cancer was the terminal event for survival calculations. Patients died within 30 days from operation and those due to unrelated reason, were excluded from the study.

\section{Immunohistochemical Analysis}

Sections $4 \mu \mathrm{m}$ thick from the paraffin-embedded tissue blocks were immunostained for HER2/neu, p53, and VEGF. The tissue sections were mounted on coated slides and dried for $1 \mathrm{~h}$ at $60^{\circ} \mathrm{C}$. The sections were deparaffinized in xylene and rehydrated in a descending ethanol series. A microwave antigen-retrieval method with $100 \mathrm{mmol} / \mathrm{l}$ citrate buffer (pH 6.0) was used. The slides were incubated with primary antibodies with dilutions of 1:160 for p53 (clone 1801; BioGenex, San Ramon, CA, USA), 1:500 for HER2/neu (Rabbit polyclnal; Dako, Carpinteria, CA, USA), and 1:500 dilution for VEGF (Rabbit polyclonal antibody, Santa Cruz Biotechnology, Santa Cruz, CA, USA). The Ventana Immunostainer and basic DAB detection system (Ventana Medical Systems, Tucson, AZ, USA) were used for the rest of the procedures. The sections were counterstained with Mayer hematoxylin, dehydrated, cleared in xylene, and mounted. All cases were run with known positive controls for each antibody. For negative controls, the primary antibody was omitted for each run.

\section{Microscopic Evaluation}

Three investigators (RSS, HH, and YL) without the knowledge of patient outcomes interpreted all slides. Discordant-independent readings were resolved by simultaneous review by the three readers. For HER2/neu, complete or almost complete staining of the entire cell periphery in $>10 \%$ of tumor cells was considered as positive. Cytoplasmic staining was considered negative. The interobserver agreement for HER2/neu was moderate (Kappa $77 \%$ ). For p53, only cases with definite nuclear staining in $>10 \%$ of tumor cells were considered as positive. The interobserver agreement for p53 was excellent (Kappa 97\%). For VEGF, cytoplasmic 
staining intensity was recorded as negative (no or $<20 \%$ of tumor cells are positive) and positive ( $>20 \%$ showing strong positivity).

\section{Statistical Analysis}

Survival data of the patients were obtained from the Laboratory Information System of Allegheny General Hospital. The survival period was calculated as the time from the date of surgery to the date of death or last follow-up. Postoperative survival curves were constructed using the Kaplan-Meier method. The association between prognostic factors (ie age, gender, HER2/neu, p53, and VEGF immunoreactivity, histotype, recurrence, vascular invasion, and death) was analyzed using multivariate analysis, taking into consideration one prognostic factor at a time. Correlation with clinical data was evaluated by Spearman's correlation. All statistical analyses were performed with SPSS (Statistical Package for Social Sciences, SPSS Inc., Chicago, IL, USA).

\section{Results}

The clinical features and morphologic findings are presented in Table 1. Figures 1-3 show the immunostaining pattern of HER2, p53, and VEGF in tumors resected from stage I conventional adenocarcinoma and bronchioloalveolar carcinoma.

\section{Conventional Adenocarcinoma Group}

The patients ranged in age from 44 to 77 years with a mean of $64 \pm 11$. There were 19 women and 31 men with mean ages of $67 \pm 7$ and $62 \pm 11$ years, respectively. According to the American Joint Committee

Table 1 Clinicomorphologic findings and results of HER2/neu, p53, and VEGF expression in stage I adenocarcinomas

\begin{tabular}{lll}
\hline & $\begin{array}{l}\text { Conventional } \\
\text { adenocarcinoma } \\
\text { (50 patients) }\end{array}$ & $\begin{array}{l}\text { Bronchioloalveolar } \\
\text { carcinoma } \\
\text { (50 patients) }\end{array}$ \\
\hline Sex & 19 women/31 men & 23 women/27 men \\
Age: range & $44-77$ years & $55-82$ years \\
Mean & $64 \pm 11$ years & $67 \pm 7$ years \\
Follow-up period & $52 \pm 20$ months & $40 \pm 17$ months \\
Histologic subtypes & 25 PD, 17 MD, 8 WD & $32 \mathrm{NM}, 18 \mathrm{M}$ \\
Stage & 23 IA/ 27 IB & $34 \mathrm{IA} / 6 \mathrm{IB}$ \\
HER2/neu expression & 19/50 positive & $9 / 50$ positive \\
p53 expression & $32 / 50$ positive & $3 / 50$ positive \\
VEGF & $33 / 50$ positive & $12 / 50$ positive \\
Fate & 17 alive & 37 alive \\
& without disease & without disease \\
& 11 with disease & 3 with disease \\
& 22 expired & 10 expired
\end{tabular}

$\mathrm{PD}=$ poorly differentiated; $\mathrm{MD}=$ moderately differentiated; $\mathrm{WD}=$ well differentiated; $\mathrm{NM}=$ bronchioloalveolar carcinoma, nonmucinous type; $\mathrm{M}=$ bronchioloalveolar carcinoma, mucinous type; VEGF $=$ vascular endothelial growth factor. on Cancer staging system, ${ }^{23}$ patients were classified as stage I (23 IA and 27 IB). The mean follow-up for patients was $52 \pm 20$ months, including $58 \pm 18$ months for women, $49 \pm 19$ for men. At the end of the study, 17 patients remained alive without disease, 11 patients alive with disease (recurrence or residual tumor), and 22 patients expired due to disease. The survival decreased with increasing age and female gender with a mean value of $29 \pm 13$ months for women and $32 \pm 17$ months for men, although this was not statistically significant. In this group, 25/50 (50\%) cases were poorly differentiated, $17 / 50(34 \%)$ cases moderately differentiated, and $8 /$ $50(16 \%)$ cases were well-differentiated adenocarcinomas.

The percentages of HER2/neu, p53 and VEGF expression were 19/50 (38\%), 32/50 (64\%), 33/50 (66\%), respectively. There was a statistical significant correlation between p53 and VEGF expression (Spearman's correlation, $r=0.52, P<0.001$ ). p53 was significantly correlated with recurrence $(r=0.34, P<0.05)$, while VEGF showed a significant correlation with vascular invasion $(r=0.31$, $P<0.05$ ). None of our immunohistochemical markers showed significant correlation with age, sex, or tumor grade.

Univariate analysis of survival for patients with stage I conventional adenocarcinoma whose tumors were positive for HER2/neu, p53, or VEGF was performed and showed significant increased mortality and decreased survival (Figures 4a and 5). The survival for patients whose tumors expressed both p53 and HER2/neu was worse than that of those who expressed only p53 or HER2/neu.

Multivariate analysis using the Cox proportional hazards regression model was performed to determine which of the factors were independent prognostic factors of lung cancer-related death. Factors in the analysis included age, sex, recurrence, angiolymphatic invasion, HER2/neu, p53, and VEGF expression. Our results showed that recurrence, angiolymphatic invasion, p53, HER2/neu, and VEGF expression emerged as independent prognostic factors.

\section{Bronchioloalveolar Adenocarcinoma Group}

The patients ranged in age from 55 to 82 years with a mean of $67 \pm 7$ years. There were 23 women and 27 men with mean ages of $67 \pm 8$ and $70 \pm 7$ years, respectively. In this group, $32 / 50$ of the neoplasms were nonmucinous subtype and 18/50 mucinous subtype. According to the American Joint Committee on Cancer staging system, ${ }^{24}$ patients were classified as stage I with 34 IA and 16 IB. The mean follow-up for patients was $40 \pm 17$ months, including $39 \pm 17$ months for women, and $42 \pm 16$ for men. At the end of the study, 37 patients remained alive without disease, three patients were alive with disease, and 10 patients expired due to disease. 

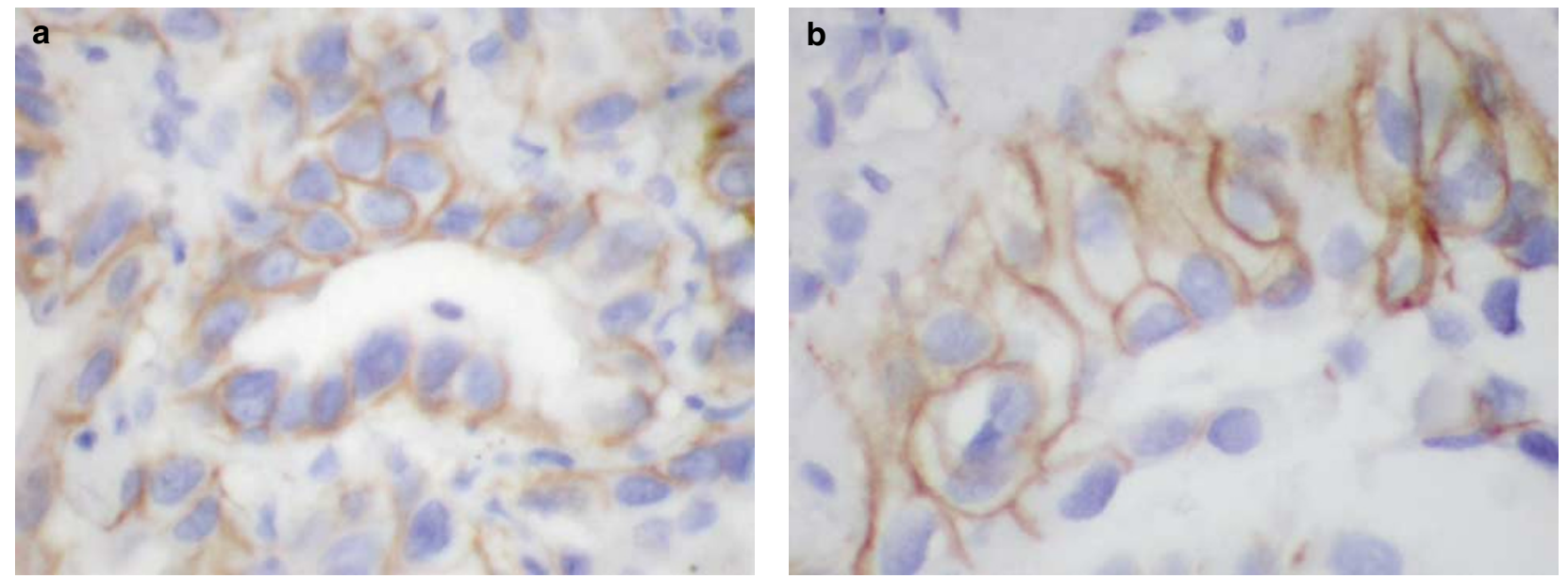

Figure 1 HER2/neu immunoreactivity in both conventional adenocarcinoma (a) and bronchioloalveolar carcinoma (b). (IHC $\times 400)$.
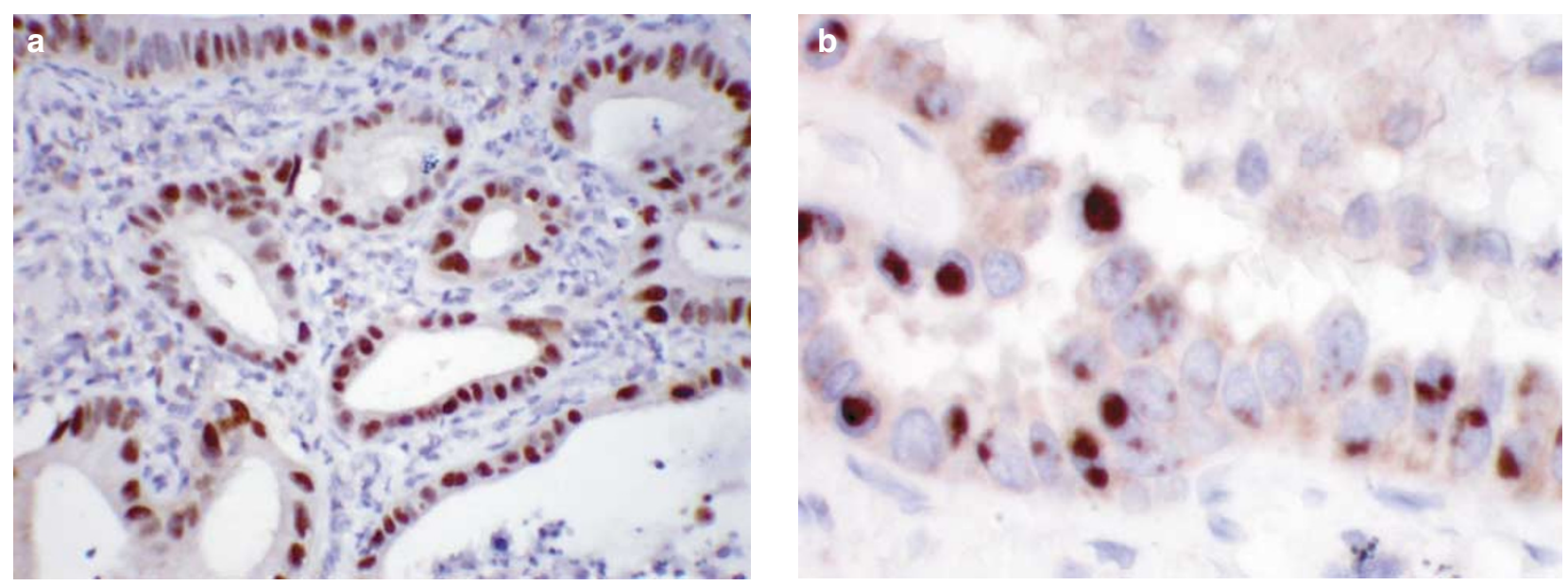

Figure 2 p53 immunoreactivity in both conventional adenocarcinoma (a) and bronchioloalveolar carcinoma (b). Note the punctuate nuclear positivity that was observed in only three cases of nonmucinous bronchioloalveolar carcinoma. (IHC $\times 400$ ).
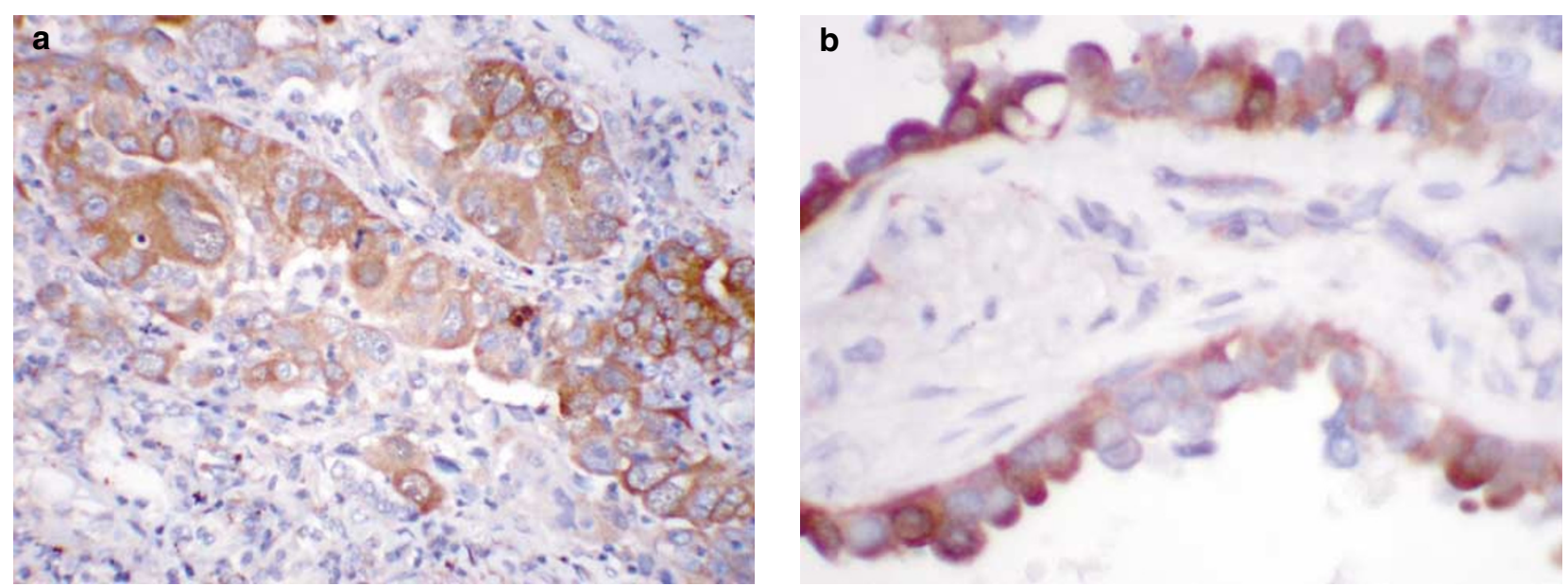

Figure 3 VEGF immunoreactivity in both conventional adenocarcinoma (a) and bronchioloalveolar carcinoma $(\mathbf{b})$. (IHC $\times 400)$.

The mean survival for patients was $40 \pm 20$ months for women and $40 \pm 18$ months for men, which was not statistically significant.
The percentages of expressions of HER2/neu, p53 and VEGF were 9/50 (18\%), 3/50 (6\%), 12/50 (24\%), respectively. These percentages of expression were 
a
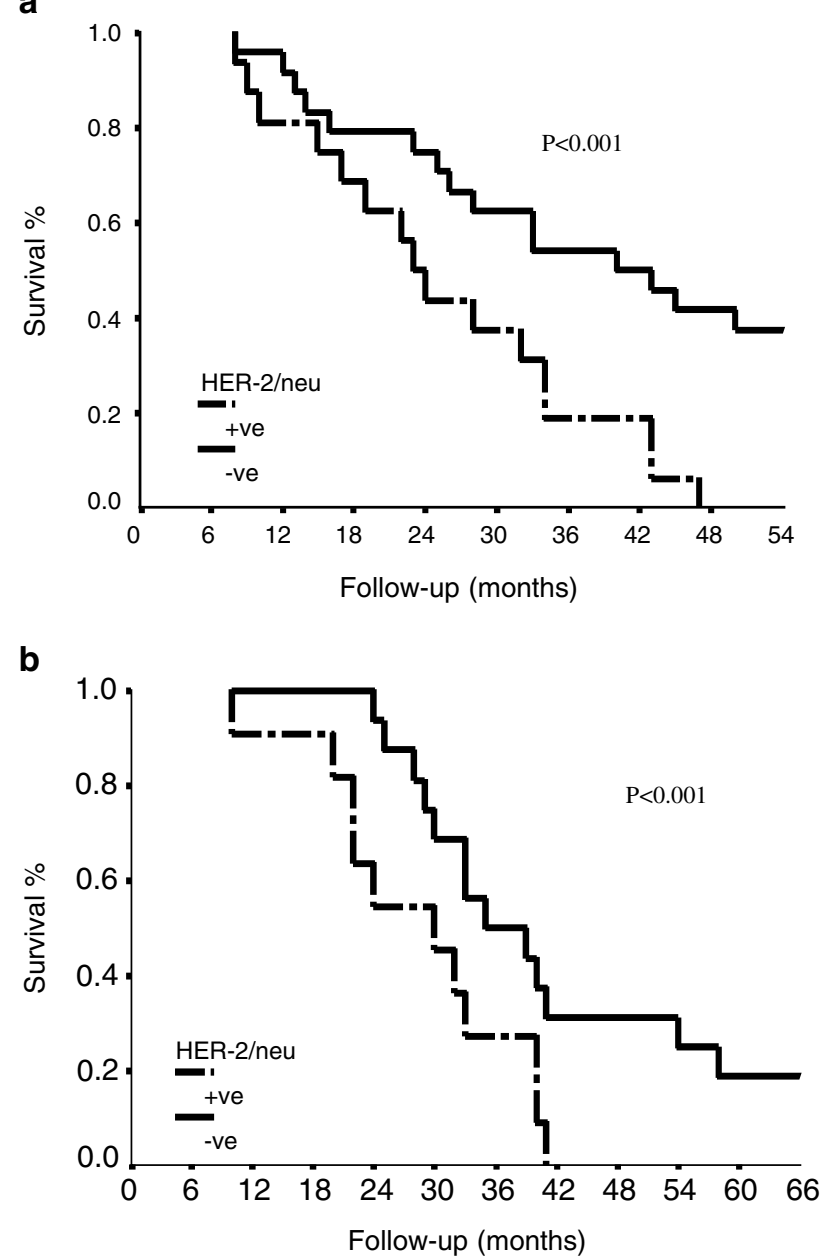

Figure 4 Survival of patients with stage I conventional adenocarcinoma (a) and bronchioloalveolar carcinoma, nonmucinous type (b) as a function of absence (solid line) or presence (dashed line) of HER2/neu overexpression.

significantly lower than that seen in conventional adenocarcinoma $(P<0.05)$. p53 was expressed only in nonmucinous type (three cases). There was no significant correlation between p53 and VEGF expression and recurrence, as shown in conventional adenocarcinoma patients. None of our immunohistochemical markers showed significant correlation with age, sex, or tumor grade.

Univariate analysis showed that only patients with HER2/neu expression in bronchioloalveolar carcinoma nonmucinous type had significant increased mortality and decreased survival (Figure 5b). Using multivariate analysis, HER2/neu emerged as an independent prognostic factor.

\section{Discussion}

Pulmonary adenocarcinoma has recently emerged as the most frequent histologic type of non-small-cell lung cancer, and its incidence has been increasing. ${ }^{6}$ a
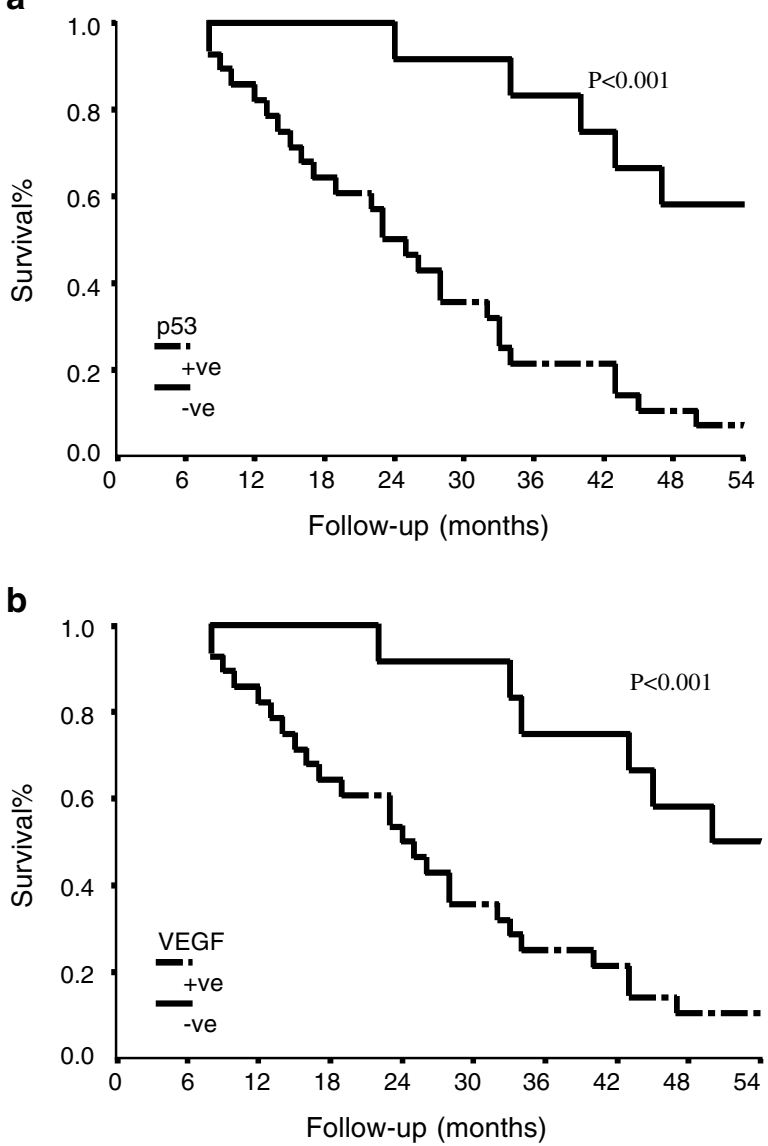

Figure 5 Survival of 50 patients with stage I conventional adenocarcinoma as a function of absence (solid line) or presence (dashed line) of p53 (a) and VEGF (b) overexpression.

Although surgical resection is the treatment of choice for stage I non-small-cell lung cancer, patients with the same stage of disease can show marked differences in survival. ${ }^{7,8}$ The purpose of this study was to investigate the value of HER2/neu, p53, and VEGF expression as possible prognostic markers in stage I conventional adenocarcinoma and bronchioloalveolar carcinoma.

HER2/neu is a proto-oncogene encoding a 185-kd transmembrane protein with tyrosine kinase activity. ${ }^{5}$ HER2/neu expression is associated mainly with high-grade breast carcinoma and considered an important prognostic factor for adverse outcomes in node-positive breast cancers. ${ }^{14,15}$ However, in non-small-cell lung cancer studies, HER2/neu expression varies depending on the histologic classification of the neoplasm. ${ }^{25-30} \mathrm{HER} 2 / \mathrm{neu}$ expression was reported in $13-80 \%$ in adenocarcinoma, ${ }^{8,29,30}$ in $2-45 \%$ in squamous cell carcinomas, ${ }^{30,31}$ and $0-20 \%$ in large-cell carcinomas. ${ }^{29}$ Consequently, different results have been reported concerning the significance of HER2/neu expression in non-small cell lung cancer. Kern et $a l,{ }^{29}$ and Tateishi et al,, reported adverse effect of HER2-neu expression, 
whereas Pfeiffer et $a l,{ }^{32}$ did not detect differences in survival. Brabender et $a l,{ }^{33}$ using a modified method were able to detect HER2/neu mRNA in 35\% of non-small-cell lung cancer patients. In their study, HER2/neu mRNA expression emerged as an independent prognostic factor for survival. The current study has found a comparable incidence of HER2/ neu expression (38\%) in stage I conventional adenocarcinoma. Furthermore, patients with HER2/neu-positive tumors had significantly decreased survival. Thus, expression of HER2/neu seems to predict aggressive tumor growth in stage I nonsmall-cell lung cancer, similar to that of breast carcinoma. ${ }^{34,35}$ Herceptin, a monoclonal antibody against HER2/neu, has been recently utilized for the treatment of HER2/neu-positive breast cancer ${ }^{36}$ and might be beneficial in HER2/neu-positive nonsmall-cell lung cancer patients. Demonstration of HER2/neu-amplification in non-small-cell lung cancer, using a standardized method, is essential for establishing clinical trials for this or other drugs. ${ }^{33}$

A few studies have investigated the prognostic implications of p53 in non-small-cell lung cancer patients, with inconsistent and contradicting results. $^{7,37-44}$ Some authors have claimed that p53 oncoprotein is an independent adverse prognostic marker, ${ }^{37-39}$ others have shown that p53 oncoprotein is an independent favorable marker for non-smallcell lung cancer, ${ }^{40,41}$ while yet others have reported that p53 oncoprotein expression has no prognostic significance. ${ }^{42-45}$ In our study, $64 \%$ (32 out of 50 ) of tumors displayed elevated p53 expression $(>10 \%$ of tumor cells with nuclear staining) and was significantly correlated with short survival and poor prognosis. Using multivariant analysis, p53 has emerged as an independent prognostic factor. These results are in agreement with previous reports. ${ }^{36-38}$ Because p53 staining is usually confined to the nuclei of the tumor cells rather than cytoplasm or cell membrane, it was easier to evaluate than HER2/ neu. In our study, the interobserver reproducibility was excellent for p53 $($ Kappa $=0.97)$ and moderate for HER2/neu (Kappa $=77 \%)$.

Reasons for the discrepant reported results in the literature are likely multifactorial, relating to the experimental techniques, diversity in the patient population studied and short clinical follow-up duration. Although all previous studies included both adenocarcinoma and squamous cell carcinoma, they analyzed different percentages of histologic subtypes of non-small-cell lung cancer. Han et al,,716 reported $70 \%$ of their patients had adenocarcinoma, while Brabender et $a l^{35}$ included only $39 \%$ of pulmonary adenocarcinoma. Piyathilake et $a l^{45}$ investigated p53 in only squamous cell carcinoma patients and found that p53 was not significantly associated with any of clinical parameters or survival. Also, bronchioloalveolar carcinoma cases was included as adenocarcinoma in these studies. In our study, we only included patients with pulmonary adenocarcinoma and compared conventional adenocarcinoma with bronchioloalveolar carcinoma subtypes.

Another possible explanation reason for discrepant results, some studies included patients with more advanced stages of non-small-cell lung cancer. The present study focused only on patients with stage I adenocarcinoma. In patients with more advanced cancer, the presence of additional pathologic abnormalities such as tumor size $>3.0 \mathrm{~cm}$, angiolymphatic invasion, and distant metastasis may trump the effects of HER-2/neu or p53 on overall survival, especially when the patient population is relatively small. Using different methods of antigen retrieval can also play a role as demonstrated by Tan et $a l,{ }^{10}$ who reported a higher percentage of adenocarcinoma positive for p53 using a microwave overheating technique. Another potential source of conflicting results is the choice of different threshold values or different monoclonal antibodies. ${ }^{14}$

VEGF is a potent angiogenic factor for neovascularization. ${ }^{16,46}$ Because tumor growth and metastasis depend primarily on neoangiogenesis, the relationship between VEGF expression and the clinical outcomes of non-small-cell lung cancer patients had been studied. ${ }^{16,47}$ Previous reports demonstrated that VEGF overexpression was associated with decreased survival, particularly in adenocarcinoma. ${ }^{47}$ Similarly, we found a significantly decreased overall survival in stage I conventional adenocarcinoma patients who demonstrated VEGF overexpression. VEGF was also associated with angiolymphatic invasion. Our study also showed a significant correlation between VEGF and p53 expression. Thus, the increased mortality in patients with stage I conventional adenocarcinoma whose tumors were positive for p53 protein in the current study might be at least partly explained by an effect of p53 on VEGF expression.

Within the bronchioloalveolar carcinoma group, we found a significant correlation between HER2/ neu and survival in the nonmucinous group, while it was not significant with p53 and VEGF. We also found a significant association between histologic type and p53 expression $(P<0.01)$, whereas p53 was significantly expressed in conventional adenocarcinoma $(64 \%)$, but not in bronchioloalveolar carcinoma (6\%). In our study, p53 was only expressed in bronchioloalveolar carcinoma, nonmucinous type (3/32 cases). Kawasaki et $a l,{ }^{48}$ and Terasaki et $a l,{ }^{5}$ also reported that p53 overexpression was rare in pure bronchioloalveolar carcinoma lesions, but more common in invasive adenocarcinoma. These results strongly indicate that p53 abnormality is associated with invasive growth of tumor cells. Kawasaki et $a l^{48}$ proposed that p53 abnormality occurred during the progression from the in situ to early invasive stage.

In conclusion, immunohistochemical staining of HER-2/neu, p53, and VEGF along with examination of vascular invasion and tumor recurrence, may aid 
in defining a subpopulation of patients with stage I conventional adenocarcinoma whose tumors may behave more aggressively. In addition, focused adjuvant therapeutic modalities and gene therapies might improve overall survival in these patients expressing the poor prognostic immunohistochemical markers.

\section{Acknowledgement}

This work was presented, in part, at the 2003 annual meeting of the American Society of Clinical Pathologists, in New Orleans, LA, USA.

\section{References}

1 Black RJ, Bray F, Ferlay J, et al. Cancer incidence and mortality in the European Union: cancer registry data and estimates of national incidence for 1990. Euro J Cancer 1997;33:105-107.

2 Travis WD, Lubin J, Ries L, et al. United States lung carcinoma incidence trends. Declining for most histologic types among males, increasing among females. Cancer 1996;77:2464-2470.

3 Ginsberg RJ, Vokes EE, Raben A. Non-small cell lung cancer. In: DeVita DT, Hellmann S, Rosenberg SA (eds). Cancer: Principles in Practice Oncology, 5th edn Lipincott-Raven: Philadelphia, 1997, pp 858-910.

4 Colby TV, Koss MN, Travis WD, (eds). Carcinoma of the lung: overview, incidence, etiology and screening. In: Atlas of Tumor Pathology: Tumors of the Lower Respiratory Tract, 3rd series, fascicle 13 Armed Forces Institute of Pathology: Washington DC, 1995, pp 91-106.

5 Terasaki H, Niki T, Matsuno Y, et al. Lung adenocarcinoma with mixed bronchioloalveolar and invasive components: clinicopathological features, subclassification by extent of invasive foci, and immunohistochemical characterization. Am J Surg Pathol 2003; 27:937-951.

6 Mountain CF. Revisions in the international system for staging of lung cancer. Chest 1997;111:1710-1713.

7 Han H, Landreneau RJ, Santucci TS, et al. Prognostic value of immunohistochemical expression of p53, HER-2/neu, and bcl-2 in stage I non-small cell lung cancer. Hum Pathol 2002;33:105-110.

8 Nesbitt JC, Putnam Jr JB, Walch GL, et al. Survival in early stage non-small cell lung cancer. Ann Thorac Surg 1995;60:466-472.

9 Harris CC, Hollstein M. Clinical implications of the p53 tumor-suppressor gene. N Engl J Med 1993;329: 1318-1327.

10 Tan DF, Li Q, Rammath N, et al. Prognostic significance of expression of p53 oncoprotein in primary (Stage I-IIIa) non-small cell lung cancer. Anticancer Res 2003;23:1665-1672.

11 Hollstein M, Sindransky D, Vogelstein B. p53 mutations in human cancer. Science 1991;253:49-53.

12 Levine AJ. The p53, the cellular gatekeeper for growth and division. Cell 1997;88:323-331.

13 Hynes NE, Stern DF. The biology of erbB-2/neu/HER-2 and its role in cancer. Biochim Biophys Acta 1994; 1198:165-184.
14 Muss HB, Thor AD, Berry DA, et al. C-erbB-2 expression and response to adjuvant therapy in women with node positive early breast cancer. N Engl J Med 1994;330:1260-1266.

15 Gusterson BA, Gelber RD, Goldhirsch A, et al. Prognostic importance of c-erbB-2 expression in breast cancer: International (Ludwig) Breast Cancer Study Group. J Clin Oncol 1992;10:1049-1056.

16 Han H, Silverman JF, Santucci TS, et al. Vascular endothelial growth factor expression in stage I non-small cell lung cancer correlates with neoangiogenesis and a poor prognosis. Ann Surg Oncol 2001; 8:72-79.

17 Ishida $\mathrm{H}$, Irie $\mathrm{K}$, Itoh $\mathrm{T}$, et al. The prognostic significance of p53 and bcl-2 expression in lung adenocarcinoma and its correlation with Ki-67 growth fraction. Cancer 1997;80:1034-1045.

18 Apolinario RM, van der Valk $\mathrm{P}$, de Jong JS, et al. Prognostic value of the expression of p53, bcl-2 and bax oncoproteins and neovascularization in patients with radically resected non-small lung cancer. J Clin Oncol 1997;15:2456-2466.

19 Giatromanolaki A, Koukourakis MI, O’Byrne K, et al. Non-small cell lung cancer: c-erbB-2 overexpression correlates with low angiogenesis and poor prognosis. Anticancer Res 1996;16:3819-3825.

20 Greatens TM, Niehans GA, Rubins JB, et al. Do molecular markers predict survival in non-small cell lung cancer? Am J Respir Crit Care Med 1998; 157:1093-1097.

21 Nishio M, Koshikawa T, Kuroishi T, et al. Prognostic significance of abnormal p53 accumulation in primary, resected non-small-cell lung cancers. J Clin Oncol 1996;14:497-502.

22 Pastorino U, Andreola S, Tagliabue E, et al. Immunocytochemical markers in stage I lung cancer: relevance to prognosis. J Clin Oncol 1997;15: 2858-2865.

23 Brambilla E, Travis WD, Colby TZ, et al. The new World Health Organization classification of lung tumors. Eur Respir J 2001;18:1059-1068.

24 Greene FL, Page DL, Fleming ID (eds). Lung. In: American Joint Committee on Cancer: AJCC Cancer Staging Manual, 6th edn, Chapter 19. Springer: New York, 2002, pp 167-177.

25 Meert AP, Martin B, Paesmans M, et al. The role of HER-2/neu expression on the survival of patients with lung cancer: a systemic review of the literature. Br J Cancer 2003;89:959-965.

26 Haque AK, Syed S, Lele SM, et al. Immunohistochemical study of thyroid transcription factor-1 and HER2/neu in nonsmall cell lung cancer: strong thyropid transcription factor-1 expression predicts better survival. Appl Immunohistochem Mol Morphol 2002;10:103-109.

27 Weiner DB, Nordberg J, Robinson R, et al. Expression of the new gene-encoded protein (p185neu) in human non-small cell carcinomas of the lung. Cancer Res 1990;50:421-425.

28 Tateishi M, Ishida T, Mitsudomi T, et al. Prognostic value of c-erbB-2 protein expression in human lung adenocarcinoma and squamous cell carcinoma. Eur J Cancer 1991;27:1372-1375.

29 Kern JA, Schwartz DA, Nordberg JE, et al. p185neu expression in human lung adenocarcinomas predicts shortened survival. Cancer Res 1990;50: 5184-5187. 
30 Yu D, Wang SS, Dulski KM, et al. C-erbB-2/neu overexpression enhances metastatic potential of human lung cancer cells by induction of metastasis-associated properties. Cancer Res 1994;54: 3260-3266.

31 Wolm M, Efferth T, Mattern J. Oncoprotein (c-myc, c-erbB1, c-erbB2, c-fos) and suppressor gene product (p53) expression in squamous cell carcinomas of the lung: clinical and biological correlations. Anticancer Res 1992;12:11-20.

32 Pfeiffer P, Clausen PP, Andersen K, et al. Lack of prognostic significance of epidermal growth factor receptor and the oncoprotein p185HER-2 in patients with systemically untreated non-small cell lung cancer: an immunohistochemical study on cryosections. Br J Cancer 1996;74:86-91.

33 Brabender J, Danenberg KD, Metzger R, et al. Epidermal growth factor receptor and HER2-neu mRNA expression in non-small cell lung cancer is correlated with survival. Clin Cancer Res 2001;7:1850-1855.

34 Ohsaki Y, Tanno S, Fujita Y, et al. Epidermal growth factor expression correlates with poor prognosis in non-small cell lung cancer patients with p53 overexpression. Oncol Rep 2000;7:603-607.

35 Tsai CM, Chang KT, Wu LH, et al. Correlations between intrinsic chemoresistance and HER-2/neu gene expression, p53 gene mutations and cell proliferation characteristics in non-small cell lung cancer cell lines. Cancer Res 1996;56:206-209.

36 Scheurle D, Jahanzeb M, Aronsohn RS, et al. HER-2/ neu expression in archival non-small cell lung carcinomas using FDA-approved Hercept test. Anticancer Res 2000;20:2091-2096.

37 Ebina M, Steinberg SM, Mulshine JL, et al. Relationship of p53 overexpression and upregulation of proliferating cell nuclear antigen with the clinical course of non-small cell lung cancer. Cancer Res 1994;54:2496-2503.
38 Fujino M, Dosaka-Akita H, Harada M, et al. Prognostic significance of p53 and ras p21 expression in nonsmall cell lung cancer. Cancer 1995;76:2457-2463.

39 Kwiatkowski DJ, Harpole DH, Godleski J, et al. Molecular pathologic substaging in 244 stage I nonsmall-cell lung cancer patients: clinical implications. J Clin Oncol 1998;16:2468-2477.

40 Passlick B, Izbicki JR, Riethmuller G, et al. P53 in non-small cell lung cancer. J Natl cancer Inst 1994;86: 801-803.

41 Lee JS, Yoon A, Kalapurakal SK, et al. Expression of p53 oncoprotein in non-small cell lung cancer: a favorable prognostic factor. J Clin Oncol 1995;13: 1893-1903.

42 Brambila E, Gazzeri S, Moro D, et al. Immunohistochemical study of p53 in human lung carcinomas. Am J Pathol 1993;143:199-210.

43 Geradts J, Fong KM, Zimmerman PV, et al. Correlation of abnormal RB, p16ink4a and p53 expression with 3p loss of heterozygosity, other genetic abnormalities, and clinical features in 103 primary non-small cell lung cancers. Clin Cancer Res 1999;5:791-800.

44 O’Byrne KJ, Cox G, Swinson D, et al. Towards a biological staging model for operable non-small cell lung cancer. Lung Cancer 2001;34:883-889.

45 Piyathilake CJ, Frost AR, Manne U, et al. Nuclear accumulation of p53 is a potential marker for the development of squamous cell lung cancer in smokers. Chest 2003;123:181-186.

46 Ferrara N. The role of vascular endothelial growth factor in pathological angiogenesis. Breast Cancer Res Treat 1995;36:127-137.

47 Ohta Y, Tomita Y, Oda M, et al. Tumor angiogenesis and recurrence in stage I non-small cell lung cancer. Ann Thorac Surg 1999;68:1034-1038.

48 Kawasaki M, Noguchi M, Morikawa A, et al. Nuclear p53 accumulation by small-sized adenocarcinomas of the lung. Pathol Int 1996;46:486-490. 